\title{
Papers
}

\section{Potential impact of public access defibrillators on survival after out of hospital cardiopulmonary arrest: retrospective cohort study}

Jill P Pell, Jane M Sirel, Andrew K Marsden, Ian Ford, Nicola L Walker, Stuart M Cobbe

\begin{abstract}
Objective To estimate the potential impact of public access defibrillators on overall survival after out of hospital cardiac arrest.

Design Retrospective cohort study using data from an electronic register. A statistical model was used to estimate the effect on survival of placing public access defibrillators at suitable or possibly suitable sites. Setting Scottish Ambulance Service.

Subjects Records of all out of hospital cardiac arrests due to heart disease in Scotland in 1991-8.

Main outcome measures Observed and predicted survival to discharge from hospital.

Results Of 15189 arrests, 12004 (79.0\%) occurred in sites not suitable for the location of public access defibrillators, $453(3.0 \%)$ in sites where they may be suitable, and $2732(18.0 \%)$ in suitable sites. Defibrillation was given in $67.9 \%$ of arrests that occurred in possibly suitable sites for locating defibrillators and in $72.9 \%$ of arrests that occurred in suitable sites. Compared with an actual overall survival of $744(5.0 \%)$, the predicted survival with public access defibrillators ranged from $942(6.3 \%)$ to $959(6.5 \%)$, depending on the assumptions made regarding defibrillator coverage.

Conclusions The predicted increase in survival from targeted provision of public access defibrillators is less than the increase achievable through expansion of first responder defibrillation to non-ambulance personnel, such as police or firefighters, or of bystander cardiopulmonary resuscitation. Additional resources for wide scale coverage of public access defibrillators are probably not justified by the marginal improvement in survival.
\end{abstract}

\section{Introduction}

Defibrillation is an independent predictor of survival after cardiac arrests that take place out of hospital, after adjustment for ambulance response time and bystander cardiopulmonary resuscitation. Within 2 minutes of arrest, two thirds of patients have electrocardiographic evidence of ventricular fibrillation or tachycardia, ${ }^{1}$ but the probability of a rhythm being amenable to defibrillation declines over time. ${ }^{2}$ Even when an ambulance meets its target response time, some delay between the emergency telephone call and attendance is inevitable. Therefore, bystander interventions must be considered together with efforts to minimise ambulance response times. To shorten time to defibrillation, locating automated external defibrillators in public places, for use by bystanders before the arrival of the ambulance, has been considered. The Department of Health is committed to providing 700 public access defibrillators in 72 sites across England and Wales. ${ }^{3}$ The present study aimed to estimate the potential impact of public access defibrillators on overall survival after out of hospital cardiopulmonary arrest.

\section{Methods}

\section{Setting}

The Scottish Ambulance Service is the sole provider of emergency pre-hospital ambulance care in Scotland. During the period of study no public access defibrillators were deployed in Scotland. Pre-hospital defibrillations were undertaken by ambulance personnel $(98.9 \%)$ or general practitioners $(1.1 \%)$.

\section{Data}

Ambulance crews collect data on all resuscitation attempts after out of hospital cardiopulmonary arrests in Scotland. The forms include the time from the emergency telephone call to the arrival of the ambulance crew at the arrest scene, location of the arrest, and whether defibrillation was performed. Since 1991 the presumed cause of arrest has been classified in accordance with the Utstein convention, whereby arrests are defined as due to cardiac disease if the cause is recorded as heart disease or unknown or the record is missing. ${ }^{4}$ Forms completed by hospital staff document whether patients admitted to hospital after cardiac arrest survive to discharge. Data from both sets of forms are collated in an electronic register at Glasgow University.

\section{Cohort study}

Our cohort comprised all out of hospital cardiopulmonary arrests over a seven year period from May 1991 that fulfilled the Utstein definition of a cardiac cause, were not witnessed by the ambulance crew, and did not occur in an ambulance, ambulance helicopter, general practice, dental surgery, or non-acute hospital. $\overline{\text { Editorial by Engdahl }}$

Department of Medical Cardiology, University of Glasgow, G31 2ER Jill P Pell honorary clinical senior lecturer Jane M Sirel research assistant Nicola L Walker senior house officer Stuart M Cobbe Walton professor of medical cardiology

Scottish Ambulance Service

Headquarters, Edinburgh

EH10 5UU

Andrew K Marsden medical director

Robertson Centre for Biostatistics,

University of

Glasgow G12 8QQ

Ian Ford

professor of statistics

Correspondence to: Stuart M Cobbe stuart.cobbe@ clinmed.gla.ac.uk

bmj.com 2002;325:515 
We reached a consensus on individual arrest sites that were suitable for locating public access defibrillators, possibly suitable (if defibrillators were to be very widely distributed), or unsuitable. In general, sites were given the benefit of doubt as to their suitability. Patients' homes were classified as unsuitable because, although automated external defibrillators are sometimes provided for use at home by patients judged to be at high risk of cardiopulmonary arrest, they are available only for personal use by trained family members and so are not accessible to the public. Unspecified sites were classified as possibly suitable. Actual survival to discharge was calculated for each of the three types of site.

\section{Statistical model}

Some patients have asystole from the onset of arrest and are unsuitable for defibrillation by the ambulance crew or bystanders. We assumed that public access defibrillators could increase the use of defibrillation up to a maximum equivalent to the use associated with early ambulance attendance-and therefore that survival would be improved, at best, to that obtained by early ambulance attendance. In each of the three suitability groups we divided arrests into those that were attended by the ambulance in $\leqslant 3$ minutes of the emergency telephone call and those that were not. We calculated actual survival for each subgroup.

We calculated predicted survival in the suitable and possibly suitable sites by applying the survival rate among patients attended in $\leqslant 3$ minutes to the number of patients who experienced a delay of $>3$ minutes.

Table 1 No of cardiopulmonary arrests (percentage of all arrests) at sites outside hospitals

\begin{tabular}{lc} 
Site & Arrests \\
\hline Not suitable for public access defibrillators: & \\
\hline Home & $9488(62.5)$ \\
\hline Public toilet & $18(0.1)$ \\
\hline Outdoor space & $204(1.3)$ \\
\hline Street & $2089(13.8)$ \\
\hline Car, taxi, truck, van & $205(1.3)$ \\
\hline Total & $12004(79.0)$ \\
\hline Possibly suitable for public access defibrillators: & $115(0.8)$ \\
\hline Bus & $20(0.1)$ \\
\hline Train & $166(1.1)$ \\
\hline Golf course & $44(0.3)$ \\
\hline Indoor space (such as multistorey car park) & $108(0.7)$ \\
\hline Unspecified & $453(3.0)$ \\
\hline Total & $10(0.1)$ \\
\hline Suitable for public access defibrillators: & $37(0.2)$ \\
\hline Bus station & $11(0.1)$ \\
\hline Train station & $1(0.0)$ \\
\hline Airport & $3(0.0)$ \\
\hline Airplane & $8(0.1)$ \\
\hline Police station & $105(0.7)$ \\
\hline Prison & $163(1.1)$ \\
\hline Church & $656(4.3)$ \\
\hline Nursing home & $37(0.2)$ \\
\hline Hotel or holiday accommodation & $274(1.8)$ \\
\hline Spectator sport venue & $516(3.4)$ \\
\hline Participation sport or keep fit venue (other than golf course) & $407(2.7)$ \\
\hline Bar, restaurant, cinema & $24(0.2)$ \\
\hline Shop, bank, office & $480(3.2)$ \\
\hline School, college, university & \\
\hline Place of work not specified elsewhere & \\
\hline Total & \\
\hline
\end{tabular}

Calculations of the predicted numbers of survivors, survival rates, and associated $95 \%$ confidence intervals were made assuming that future arrests would have the same distribution of arrest sites and attendance times as the cohort data. We calculated two predicted overall survival rates, according to location of public access defibrillators only in suitable sites or in both suitable and possibly suitable sites. We calculated standard errors and 95\% confidence intervals for predicted survival rates by propagating the binomial error from estimating the survival rates in the site groups and the time from emergency call to ambulance arrival through the formula for the estimated rates.

\section{Results}

Cohort study

Over the seven year study period, 21481 cardiopulmonary arrests were attended by the Scottish Ambulance Service, and 15189 fulfilled the inclusion criteria. Of these, 12004 (79.0\%) occurred in sites not suitable for the location of public access defibrillators, such as the person's home or a friend's home, 453 $(3.0 \%)$ occurred in possibly suitable sites, such as buses and multistorey car parks, and $2732(18.0 \%)$ occurred in suitable sites, such as shops, places of business, and sports centres (table 1). The 453 possibly suitable sites included 105 sites recorded only as "other" and three cases in which no information on site was recorded.

Data on defibrillation and outcome were available for 14947 (98.4\%) arrests. Of these, 8895 (59.5\%) people received defibrillation from the ambulance crew (table 2). However, the proportion of people who received defibrillation varied significantly between unsuitable, possibly suitable, and suitable sites $(\mathrm{P}<0.0001)$. Just over half $(56.2 \%)$ of the patients who had an arrest in sites not suitable for public access defibrillators received defibrillation, compared with $67.9 \%$ in possibly suitable sites and $72.9 \%$ in suitable sites. Less than $1 \%$ of patients who were not in ventricular tachycardia or fibrillation survived, irrespective of site of arrest. In all types of site, patients who received defibrillation were significantly more likely to survive. People who had an arrest in sites suitable for public access defibrillators had the highest baseline survival rate.

Overall, $70.1 \%$ of patients who were attended in $\leqslant 3$ minutes received defibrillation, compared with 58.3\% in patients who experienced longer delays $(\mathrm{P}<0.0001)$ (table 3). Among the 14850 patients with complete data on ambulance response time and defibrillation, 744 (5.0\% (95\% confidence interval $4.7 \%$ to $5.4 \%)$ ) survived to discharge from hospital.

\section{Statistical model}

The model predicted that locating public access defibrillators only in suitable sites would increase the number of survivors from 744 to 942 , a survival rate of $6.3 \%(5.6 \%$ to $7.1 \%)$. If defibrillators were located in suitable and possibly suitable sites, the predicted number of survivors increased only slightly further to 959 , a survival rate of $6.5 \%(5.7 \%$ to $7.2 \%)$ (table 3$)$. In Scotland, with a population of 5.1 million, these rates equate to an average number of additional lives saved a year of 28 and 31, respectively.

A response time cut-off of 2 minutes rather than 3 minutes produced a predicted number of survivors of 
Table 2 Numbers of cardiopulmonary arrests and of patients who survived to discharge, by suitability of site for public access defibrillators

\begin{tabular}{|c|c|c|c|c|c|c|}
\hline \multirow[b]{2}{*}{ Site } & \multicolumn{2}{|r|}{ Defibrillation } & \multicolumn{2}{|c|}{ No defibrillation } & \multicolumn{2}{|c|}{ All cardiac arrests } \\
\hline & Arrests & Survived to discharge & Arrests & Survived to discharge & Arrests & Survived to discharge \\
\hline \multicolumn{7}{|l|}{ Not suitable } \\
\hline Home & 4880 & 285 & 4509 & 26 & 9389 & 311 \\
\hline Public toilet & 10 & 0 & 8 & 1 & 18 & 1 \\
\hline Outdoor space & 117 & 6 & 82 & 0 & 199 & 6 \\
\hline Street & 1515 & 163 & 510 & 4 & 2025 & 167 \\
\hline Car, taxi, truck, van & 123 & 12 & 75 & 0 & 198 & 12 \\
\hline Total $(\%, 95 \% \mathrm{Cl})$ & 6645 & $466(7.0,6.4$ to 7.7$)$ & 5184 & $31(0.6,0.4$ to 0.8$)$ & 11829 & $497(4.2,3.8$ to 4.6$)$ \\
\hline \multicolumn{7}{|l|}{ Possibly suitable } \\
\hline Bus & 81 & 4 & 33 & 1 & 114 & 5 \\
\hline Train & 14 & 2 & 6 & 0 & 20 & 2 \\
\hline Golf course & 120 & 6 & 44 & 0 & 164 & 6 \\
\hline Indoor space & 21 & 1 & 23 & 0 & 44 & 1 \\
\hline Unspecified & 68 & 6 & 38 & 0 & 106 & 6 \\
\hline Total $(\%, 95 \% \mathrm{Cl})$ & 304 & $19(6.3,3.8$ to 9.6$)$ & 144 & $1(0.7,0.0$ to 3.8$)$ & 448 & $20(4.5,2.7$ to 6.8$)$ \\
\hline \multicolumn{7}{|l|}{ Suitable } \\
\hline Bus station & 7 & 0 & 2 & 0 & 9 & 0 \\
\hline Train station & 28 & 4 & 8 & 0 & 36 & 4 \\
\hline Airport & 8 & 1 & 2 & 0 & 10 & 1 \\
\hline Airplane & 1 & 0 & 0 & 0 & 1 & 0 \\
\hline Police station & 2 & 1 & 1 & 0 & 3 & 1 \\
\hline Prison & 5 & 1 & 3 & 0 & 8 & 1 \\
\hline Church & 83 & 10 & 15 & 0 & 98 & 10 \\
\hline Nursing home & 63 & 1 & 98 & 0 & 161 & 1 \\
\hline Hotel, holiday accommodation & 406 & 29 & 245 & 3 & 651 & 32 \\
\hline Spectator sport venue & 32 & 17 & 4 & 0 & 36 & 17 \\
\hline Participation sport venue & 224 & 37 & 47 & 0 & 271 & 37 \\
\hline Bar, restaurant, cinema & 416 & 42 & 88 & 1 & 504 & 43 \\
\hline Shop, bank, office & 332 & 42 & 60 & 1 & 392 & 43 \\
\hline School, college, university & 19 & 3 & 5 & 0 & 24 & 3 \\
\hline Other place of work & 320 & 38 & 146 & 2 & 466 & 40 \\
\hline Total $(\%, 95 \% \mathrm{Cl})$ & 1946 & $226(11.6,10.2$ to 13.0$)$ & 724 & $7(1.0,0.4$ to 2.0$)$ & 2670 & $233(8.7,7.7$ to 9.9$)$ \\
\hline Overall total & 8895 & $711(8.0,7.4$ to 8.6$)$ & 6052 & $39(0.6,0.5$ to 0.9$)$ & $14947^{*}$ & $750(5.0,4.7$ to 5.4$)$ \\
\hline
\end{tabular}

*Excludes 13 patients with missing data on defibrillation and 229 patients with missing outcome.

$1008(6.8 \%(5.6 \%$ to $7.9 \%))$ for suitable sites only and $1028(6.9 \%(5.7 \%$ to $8.1 \%))$ for suitable and possibly suitable sites. A cut-off of 4 minutes produced figures of $892(6.0 \%(5.7 \%$ to $6.3 \%))$ and $903(6.1 \%(5.5 \%$ to $6.7 \%))$.

\section{Discussion}

Our results show the limited impact of public access defibrillators on overall survival after cardiopulmonary arrest in a population. Most cardiopulmonary arrests occur in sites that are not suitable for locating public access defibrillators. Arrests that occur in obvious sites for locating defibrillators already have the shortest ambulance response times and the highest rate of defibrillation.

\section{Reducing time to defibrillation}

Nearly all survivors of out of hospital cardiopulmonary arrest are in ventricular fibrillation when the ambulance arrives, because asystole and pulseless electrical activity usually imply a prolonged interval from the onset of initial ventricular fibrillation or the presence of irreversible cardiac damage. ${ }^{5}$ The proportion of patients in ventricular fibrillation is inversely associated with time from cardiac arrest, with no evidence of a threshold effect. ${ }^{2}{ }^{6}$ Therefore, any intervention that reduces time to defibrillation should increase the proportion of patients suitable for defibrillation and improve survival.

The American Heart Association proposed four strategies to reduce time to defibrillation. ${ }^{6}$ Traditional

Table 3 Actual survival and predicted survival (assuming availability of public access defibrillators) by suitability of site of cardiopulmonary arrest for public access defibrillator. Figures are numbers (percentages) of arrests unless stated otherwise

\begin{tabular}{|c|c|c|c|c|c|c|c|c|c|c|c|}
\hline \multirow[b]{2}{*}{ Site } & \multicolumn{3}{|c|}{ Response time $\leqslant 3$ min } & \multicolumn{3}{|c|}{ Response time $>3 \mathrm{~min}$} & \multirow[b]{2}{*}{$\begin{array}{c}\text { Overall } \\
\text { total }\end{array}$} & \multicolumn{2}{|c|}{ Actual overall survival } & \multicolumn{2}{|c|}{ Predicted overall survival* } \\
\hline & Total & $\begin{array}{c}\text { Patients } \\
\text { defibrillated }\end{array}$ & $\begin{array}{l}\text { Patients } \\
\text { survived }\end{array}$ & Total & $\begin{array}{c}\text { Patients } \\
\text { defibrillated }\end{array}$ & $\begin{array}{l}\text { Patients } \\
\text { survived }\end{array}$ & & No & $\%(95 \%$ CI) & No & $\%(95 \% \mathrm{CI})$ \\
\hline Not suitable & 1136 & $739(65.1)$ & $113(9.9)$ & 10625 & $5867(55.2)$ & $381(3.6)$ & 11761 & 494 & 4.2 (3.8 to 4.6$)$ & 494 & 4.2 (3.8 to 4.6$)$ \\
\hline Possibly suitable & 48 & $36(75.0)$ & $4(8.3)$ & 395 & $265(67.1)$ & $16(4.1)$ & 443 & 20 & 4.5 (2.6 to 6.4$)$ & 37 & 8.3 (0.5 to 16.2$)$ \\
\hline Suitable & 340 & $294(86.5)$ & $55(16.2)$ & 2306 & $1633(70.8)$ & $175(7.6)$ & 2646 & 230 & 8.7 (7.6 to 9.8$)$ & 428 & 16.2 (12.3 to 20.1$)$ \\
\hline All sites & 1524 & $1069(70.1)$ & $172(11.3)$ & 13326 & $7765(58.3)$ & $572(4.3)$ & $14850 \dagger$ & 744 & 5.0 (4.7 to 5.4$)$ & 959 & 6.5 (5.7 to 7.2$)$ \\
\hline
\end{tabular}

${ }^{*}$ Model assumes that survival among patients where the response time was $>3$ minutes becomes equivalent to that in the $\leqslant 3$ minute group were public access defibrillators to be available at suitable or possibly suitable sites.

†Excludes 13 patients with missing data on defibrillation, 97 with missing response time, and 119 with missing outcome. 
first responders other than ambulance crews (such as police and firefighters) could be provided with automated external defibrillators and trained in their use. In Scotland provision of automated external defibrillators to other first responders could double overall survival to discharge from hospital. ${ }^{7}$

Formal training could be given to personnel not in the traditional emergency services-flight attendants, security personnel, and voluntary workers. $^{89}$ An Australian airline installed automated external defibrillators in its aircraft and the airports it used. ${ }^{10}$ Over a period of 64 months 46 arrests occurred, 23 from ventricular fibrillation. Twenty one of these patients were successfully defibrillated and six survived. Similar results were reported in a more recent study of automated external defibrillators in a US airline. ${ }^{8}$ In a 32 month study on the use of automated external defibrillators by trained security personnel in 32 casinos, 148 people had a confirmed cardiac arrest. Defibrillators were used on 105 people whose initial cardiac rhythm was ventricular fibrillation. Overall 56 survived to discharge from hospital.

Automated external defibrillators could be provided to people at high risk of cardiopulmonary attack and to friends and family members trained in their use. Almost two thirds of all arrests occur in patients' own homes, and patients who have recently suffered a myocardial infarction or non-fatal arrest are at increased risk of cardiopulmonary arrest. However, these defibrillators would not be publicly available and would not reduce time to defibrillation among people not identified as at high risk or people in whom cardiopulmonary arrest is the first manifestation of cardiovascular disease, who account for most cardiopulmonary arrests in the population.

Finally, automated external defibrillators could be located in public places for use by the general public, most of whom will have little or no training in their use. This option is analogous to the situation in relation to fire extinguishers, which are widely distributed throughout public buildings. Public access defibrillators would need to take the form of simple, "intelligent" devices that require minimal training and maintenance and could be supported by telephone or interactive instruction.

\section{Cost effectiveness}

Making public access defibrillators as widely available as fire extinguishers would greatly increase early access but would incur considerable costs and would be problematic in terms of maintenance and avoiding misuse and vandalism. Nichol et al modelled the incremental cost effectiveness of expanding access to automated external defibrillators beyond the emergency medical services in the United States. ${ }^{11}$ Their model excluded the $25 \%$ of arrests in the United States that occur in non-urban areas. They reported a baseline survival of $7.9 \%$, which increased to a predicted $8.7 \%$ with lay responder defibrillation and to $11.8 \%$ with the police as additional first responders. The incremental costs per patient treated were estimated as $\$ 7100$ ( $£ 4590$; $€ 7148$ ) and $\$ 9200$, respectively, and the cost per additional quality adjusted life year (QALY) was $\$ 44000$ and $\$ 27200$. The authors concluded that these costs were similar to those of a number of existing medical interventions. However, their lay responder model

\section{What is already known on this topic}

Three quarters of all deaths from acute coronary events occur before the patient reaches a hospital

Defibrillation is an independent predictor of survival from out of hospital cardiac arrest

The probability of a rhythm being amenable to defibrillation declines with time

Interest in providing public access defibrillators to reduce the time to defibrillation has been growing, but their potential impact on overall survival is unknown

\section{What this study adds}

Most arrests occur in sites unsuitable for locating public access defibrillators

Arrests that occur in sites suitable for locating defibrillators already have the best profile in terms of ambulance response time, use of defibrillation, and survival of the patient

Public access defibrillators are less likely to increase survival than expansion of first responder defibrillation or bystander cardiopulmonary resuscitation

used costs from a police responder pilot. It is likely that the cost per QALY of a public access scheme will be much higher, owing to the large number of defibrillators needed to provide adequate coverage. Unlike automated external defibrillators used by a police service, public access defibrillators are fixed to a location, and the location of future arrests cannot be predicted precisely from the location of previous arrests.

\section{Conclusions}

Targeted placement of defibrillators in public places such as airports and shopping centres, frequented by a large number of susceptible people, could, at best, increase overall survival from $5.0 \%$ to $6.3 \%$. These sites are the most suitable for locating public access defibrillators on grounds of effectiveness, cost effectiveness, maintenance, and training. People working in these areas could be trained in their use, rather than relying on the actions of untrained bystanders. Further expansion of the coverage of public access defibrillators to enable lay use in all potentially suitable sites would require much greater resources and would produce little additional improvement in survival. Public access defibrillators should not be provided in preference to the expansion of defibrillation given by first responders or increased cardiopulmonary resuscitation by bystanders.

Contributors: SMC and AKM had the original idea for the study. SMC and JPP agreed the study design. JMS and NLW collated and processed the data. JPP and JMS undertook the analyses with advice from IF. JPP produced the first draft. All authors made comments on the paper, which was redrafted by JP. All authors agreed the interpretation of the results and read and approved the final draft. SMC is the guarantor.

Funding: British Heart Foundation.

Competing interests: None declared. 
1 Sedgwick ML, Dalziel K, Watson J, Carrington DJ, Cobbe SM. The causative rhythm in out-of-hospital cardiac arrests witnessed by the emergenc medical services in the Heartstart Scotland Project. Resuscitation 1994;27:55-9.

2 Wilcox-Gok VL. Survival from out-of-hospital cardiac arrest. Med Care 1991;29:104-14.

3 Secretary of State for Health. Saving lives: our healthier nation. London: Department of Health, 1999.

4 Cummins RO, Chamberlain DA, Abramson NS, Allan M, Baskiett PJ, Becker L, et al. Recommended guidelines for uniform reporting of data from out-of-hospital cardiac arrest: the Utstein Style. A statement for health professionals from a task force of the American Heart Association, the European Resuscitation Council, the Heart and Stroke Foundation of Canada and the Australian Resuscitation Council c Cir 1991:84:960-75

5 Weaver WD, Hill D, Farhrenbruch ED, Coppas MK, Martin JS, Cobb LA, et al. Use of the automatic external defibrillator in the management of out-of-hospital cardiac arrest. N Engl J Med 1988;319:661-6.

6 Nichol G, Hallstrom AP, Kerber R, Moss AJ, Ornato JP, Palmer D, et al American Heart Association report on the second public access defibrilation conference, April 17-19, 1997. Circulation 1998;97:1309-14.
7 Pell JP, Sirel JM, Marsden AK, Ford I, Cobbe SM. Effect of reducing ambulance response times on deaths from out of hospital cardiac arrest: cohort study. BMJ 2001;322:1385-8.

8 Page RL, Joglar JA, Kowal RC, Zagrodzky JD, Nelson LL, Ramaswamy K, et al. Use of automated external defibrillators by a US airline. NEngl J Med 2000;343:1210-6

9 Valenzuela TD, Roe DJ, Nicol G, Clark LL, Spaite DW, Hardman RG. Outcomes of rapid defibrillation by security officers after cardiac arrest in casinos. N Engl J Med 2000;343:1206-9.

10 O'Rourke MF, Donaldson E, Geddes JS. An airline cardiac arrest program. Circulation 1997;96:2849-53.

11 Nichol G, Hallstrom AP, Ornato JP, Riegel B, Stiell IG, Valenzuela T, et al. Potential cost-effectiveness of public access defibrillation in the United States. Circulation 1998;97:1315-20.

(Accepted 2 April 2002) 